\title{
Francis Fukuyama
}

\section{Identidad. La demanda de dignidad y \\ las políticas de resentimiento \\ Editorial: Deusto. $1^{a}$ edición en español, Barcelona, España. \\ Año: 2019. 206 pp. ISBN: 978-84-234-3028-4}

\section{Roberto Lagos Flores ${ }^{1}$}

Este libro, titulado Identidad. La demanda de dignidad y las politicas de resentimiento, originalmente en idioma inglés (2018) y editado por primera vez en español (2019), presenta un registro de materias que siempre han acompañado a su autor como democracia, inmigración, instituciones políticas, pero esta vez conectados por el hilo conductor del concepto de identidad, acaso el más poderoso motor de la sociedad contemporánea. En efecto, el concepto de identidad es revisado por Fukuyama a lo largo de catorce capítulos desde el punto de vista histórico, cultural, político, institucional, pero especialmente es mirado desde los efectos que representa para la política contemporánea. Dice Fukuyama en varios pasajes del libro que la política de la identidad es el lente a través del cual se miran los problemas sociales y la política a nivel global.

Cabe recordar que Francis Fukuyama es un célebre Cientista Político de origen japonés nacido en Chicago en 1952 en Estados Unidos; se hizo mundialmente conocido por su artículo «El Fin de la Historia" publicado en The National Interest y luego por su libro El Fin de la Historia y el último hombre (1994). De hecho, la elaboración de esta obra Identidad es, en palabras del propio autor, una forma de retomar algo escrito al final del libro sobre el Fin de la Historia, en torno a una pregunta que él dejó abierta: si el sistema moderno de democracia liberal puede ofrecer salidas al deseo de reconocimiento moderno de ser visto y apreciado como alguien superior

1 Cientista político de la Pontificia Universidad Católica de Chile. Magíster en Sociología. Cursa un doctorado en la Facultad de Filosofía de los Valores y Antropología Social de la Universidad del País Vasco, España. ID ORCID: https://orcid.org/0000-0001-95233349. Correo electrónico: rrlagos@uc.cl / roberto.lagos@utem.cl. al resto, no en condiciones de igualdad, sino más bien como superior a otros. En efecto, la elaboración de este libro se origina en cabos pendientes de ese libro y se complementa con lo que representó el ascenso al poder de Donald Trump como presidente de Estados Unidos (2017-2021).

Ahora bien, la identidad es explicada en los primeros capítulos del libro, y es, según su autor, una distinción entre un "yo interior» $\mathrm{y}$ "el mundo exterior», este último posee normas, reglas y leyes, modela las formas sociales, por lo tanto, si ese mundo externo no reconoce públicamente como valioso a ese yo interior se produce un desajuste, un conflicto, un malestar, el cual es catalogado por el individuo o grupo como incorrecto, injusto, un menoscabo. Y como la dignidad históricamente se les atribuyó a grupos reducidos de personas, muy específicos y minoritarios, lo que ocurre en la sociedad moderna es que este reconocimiento público se desea para la mayoría y, por ende, se califica de denigrante, tardío e indigno cuando no abarca a todos los grupos sociales. Los individuos desean saberse valiosos y ser reconocidos como valiosos. Todo este análisis lo hace Fukuyama incorporando principalmente aspectos de la psicología humana, en contraste con el predominio de la economía en el análisis de la realidad social, la que ha sido hegemónica en el estudio social y político del mundo contemporáneo. El propio autor califica de simple y reduccionista al análisis económico clásico cuando intenta comprender de modo universal las necesidades y motivaciones humanas actuales, como por ejemplo considerar la valía de la persona humana. La elite académica, los planificadores sociales y la dirigencia política han pasado por alto este hecho y se olvidan de la importancia de los recursos inmateriales: la necesidad de reconocimiento por parte de los demás es uno de 
ellos. En consecuencia, el reconocimiento ya no es exclusivo para una elite (o solo para los guerreros que en el mundo clásico poseían la dignidad en la esfera pública), ahora cada alma humana lo necesita: igualdad de trato a las mujeres, multiculturalismo o deseo de reconocimiento de la raza.

Las políticas de identidad también deben ser ejecutadas de manera justa y no problemática, éstas no pueden quedarse en la superficialidad de reconocer toda forma específica como valorable para la sociedad, porque dirigirse hacia grupos minoritarios, estrechos y particularistas hace perder de vista a grupos mayoritarios que por ese simple efecto pasan a sentirse postergados; algo de eso pasó con la gran clase obrera estadounidense blanca que se volcó hacia Trump debido a que se sintieron marginados de las elites demócratas por mucho tiempo, como también ocurre cuando los medios de comunicación privilegian a unos individuos por sobre otros, por ejemplo, los desempleados, las clases medias, la vida en el mundo rural que se concibe como opuesta al cosmopolitismo, pero es igual de valiosa; igualmente, el amplio mucho cristiano y de evangélicos que es censurado u opacado, especialmente por los medios de masas. En definitiva, hay que buscar en las políticas del reconocimiento un correcto y justo equilibrio en cuestiones de identidad. Las nuevas identidades de derecha surgen con fuerza contra esta contracara de la moneda que es la identidad y el deseo de reconocimiento. También son peligrosos a juicio de Fukuyama las políticas de censura contra la opinión mayoritaria: "Que un argumento resulte ofensivo para la autoestima de alguien se considera a menudo suficiente razón para deslegitimarlo, una tendencia que las comunicaciones breves, propagadas por las redes sociales no hace más que acentuar» (132).

Fukuyama también dedica un capítulo del libro a tratar la cuestión de la identidad nacional, y pese al reconocimiento que hace el autor de la importancia de la diversidad interna en los países, lo que es positivo para la resiliencia, los valores y la cultura, la identidad nacional hace dinámicos y poderosos a los países, como Japón y Corea; más seguros frente a las amenazas como Canadá o Estados Unidos; es capaz de mejorar la calidad de los gobiernos, porque hay menos grupos internos, ya sea étnicos o de raza, que corrompen el Estado para su propios grupos de interés; facilita el desarrollo económico como en China; por el contrario, sociedades divididas que compiten de modo egoísta por los recursos públicos caen en el caos; finalmente, es positiva la identidad nacional porque ayuda a consolidar la democracia liberal, pues fortalece el contrato social, con deliberación y debate público. En suma: «las democracias no sobrevivirán si los ciudadanos no se sienten, en cierta medida, apegados irracionalmente a las ideas del gobierno constitucional y la igualdad humana por medio de unos sentimientos de orgullo y patriotismo» (147).

Esta lectura de Fukuyama es muy explicativa y elocuente. La gran lección de esta obra radica en darse cuenta del cambio social de las últimas décadas en que las cuestiones de identidad se han convertido en la base de la discusión pública que delimita los debates dejando en un segundo plano los asuntos económicos y de bienestar material que predominaron en el siglo pasado. Esto explica en gran medida las tensiones políticas actuales. El poder de las clases medias desesperadas y no de los pobres marginados es una muestra del anhelo de reconocimiento y de la identidad, las revoluciones no son campesinas y de pobres, bien lo explica Fukuyama, los movimientos sociales más violentos son llevados a cabo por las clases medias que ven un ascenso social imposible, ven que sus perspectivas de crecer se reducen y por ello se levantan contra el poder. Los casos actuales de Chile, Colombia, Ecuador y diversos países de Latinoamérica, que han debido enfrentar movimientos de protesta y de violencia urbana, se podrían explicar mejor por la ausencia de reconocimiento a esta amplia clase media, universitaria, con recursos, con capacidades para movilizarse políticamente, pero que han visto mermado su desarrollo y exigen derechos y un aseguramiento a su condición de seres humanos, exigiendo sobre todo ser respetados por la sociedad, ser reconocidos como sujetos, orgullosos de su vivencia y no desesperados por su supervivencia. Por eso que esta obra debe ser bien apreciada y es tan actual como provechosa. La amenaza que perciben las personas en la pérdida de su estatus es un claro ejemplo de la importancia de la identidad. Hay múltiples movimientos contra las elites que quieren ser atendidos por las instituciones del Estado, por los medios de comunicación y la opinión pública; se hartaron de ser abusados. Tales fenómenos se 
relacionan con lo que constituye el núcleo del ensayo de Fukuyama: la necesidad que tienen sectores importantes de la población de que se reconozca su identidad y su dignidad, lo que es tanto como enaltecer sus peculiaridades individuales y sociales. En definitiva, esta publicación viene a añadir otra pieza más a su vasta obra en que se preocupa de las instituciones y de la calidad de la democracia, sus deficiencias y debilidades. Tiene razón la editorial Deusto al catalogar en la contraportada del libro: «Si quieres entender la política del siglo XXI, éste es tu libro». No es una exageración. 